Supporting Information Available for

\title{
Characterizing the dimerization of phenalenyl radicals
}

by ab initio calculations and spectroscopy:

$\sigma$-Bond formation vs resonance $\pi$-stabilization.

\author{
D. Small, ${ }^{\text {a }}$ S.Rosokha, ${ }^{\mathrm{b}}$ J. K. Kochi ${ }^{\mathrm{b}}$ and M. Head-Gordon ${ }^{\mathrm{a}}$ \\ ${ }^{a}$ Departments of Chemistry, University of California, Berkeley, CA, 94720 \\ and ${ }^{b}$ University of Houston, Houston, TX, 77004
}

Dimerization energetics (Tables S1-S4), $<\mathrm{S}^{2}>$ values for the unrestricted calculations (Table S5), and geometries of the three unique RR- and two unique RS-isomers of $\sigma-\mathbf{P}_{\mathbf{2}}$ (PDB files), and the temperature-dependent ESR spectra of radicals $\mathbf{4}^{\bullet}$ (Figure S1) and $\mathbf{1}^{\circ}$ (Figure S2). 
Table S1. Electronic energy change $\left(\mathrm{kcal} \mathrm{mol}^{-1}\right)$ for transformation (1) and binding energy for the RR1 dimer.

\begin{tabular}{ccc}
\hline Method & $\Delta \mathrm{E}(1)^{\mathrm{a}}$ & $\mathrm{E}(\mathrm{RR} 1)^{\mathrm{b}}$ \\
\hline RHF & -6.45 & 10.90 \\
RMP2 & 3.48 & 20.83 \\
UHF & -5.74 & 11.61 \\
UMP2 & 0.72 & 18.07 \\
UB3LYP & -4.37 & 12.98
\end{tabular}

(a) For (1) in Scheme 2 computed by the method in column 1 and $6-31 \mathrm{G}^{*}$ basis.

(b) Obtained by adding electronic energy for (2) in Scheme 2 to the result in column 2.

Table S2. Electronic energy change $\left(\mathrm{kcal} \mathrm{mol}^{-1}\right)$ for transformation (1) and binding energy for the RR2 dimer.

\begin{tabular}{ccc}
\hline Method & $\Delta \mathrm{E}(1)^{\mathrm{a}}$ & $\mathrm{E}(\mathrm{RR} 2)^{\mathrm{b}}$ \\
\hline RHF & -6.04 & 11.31 \\
RMP2 & 2.02 & 19.37 \\
UHF & -5.96 & 11.39 \\
UMP2 & 0.00 & 17.35 \\
UB3LYP & -4.38 & 12.97
\end{tabular}

(a) For (1) in Scheme 2 computed by the method in column 1 and 6-31G* basis.

(b) Obtained by adding electronic energy for (2) in Scheme 2 to the result in column 2.

Table S3. Electronic energy change $\left(\mathrm{kcal} \mathrm{mol}^{-1}\right)$ for transformation (1) and binding energy for the RS1 dimer.

\begin{tabular}{ccc}
\hline Method & $\Delta \mathrm{E}(1)^{\mathrm{a}}$ & $\mathrm{E}(\mathrm{RS} 1)^{\mathrm{b}}$ \\
\hline RHF & -6.30 & 11.05 \\
RMP2 & 2.47 & 19.82 \\
UHF & -5.74 & 11.61 \\
UMP2 & 0.27 & 17.62 \\
UB3LYP & -4.36 & 12.99
\end{tabular}

(a) For (1) in Scheme 2 computed by the method in column 1 and $6-31 \mathrm{G}^{*}$ basis.

(b) Obtained by adding electronic energy for (2) in Scheme 2 to the result in column 2. 
Table S4. Electronic energy change $\left(\mathrm{kcal} \mathrm{mol}^{-1}\right)$ for transformation (1) and binding energy for the RS2 dimer.

\begin{tabular}{ccc}
\hline Method & $\Delta \mathrm{E}(1)^{\mathrm{a}}$ & $\mathrm{E}(\mathrm{RS} 2)^{\mathrm{b}}$ \\
\hline RHF & -3.39 & 13.96 \\
RMP2 & 4.26 & 21.61 \\
UHF & -3.01 & 14.34 \\
UMP2 & 2.60 & 19.95 \\
UB3LYP & -2.34 & 15.01
\end{tabular}

(a) For (1) in Scheme 2 computed by the method in column 1 and 6-31G* basis.

(b) Obtained by adding electronic energy for (2) in Scheme 2 to the result in column 2.

Table S5. $<\mathrm{S}^{2}>$ values for unrestricted calculations $\mathrm{s}^{\mathrm{a}}$.

\begin{tabular}{ccc}
\hline Isomer & UHF & UB3LYP \\
\hline Monomer & 2.08 & 0.80 \\
RR1 & 3.20 & 0.0 \\
RR2 & 3.16 & 0.0 \\
RR3 & 3.17 & 0.0 \\
RS1 & 3.19 & 0.0 \\
RS2 & 3.17 & 0.0
\end{tabular}

(a) Performed at optimized geometries of listed method. 


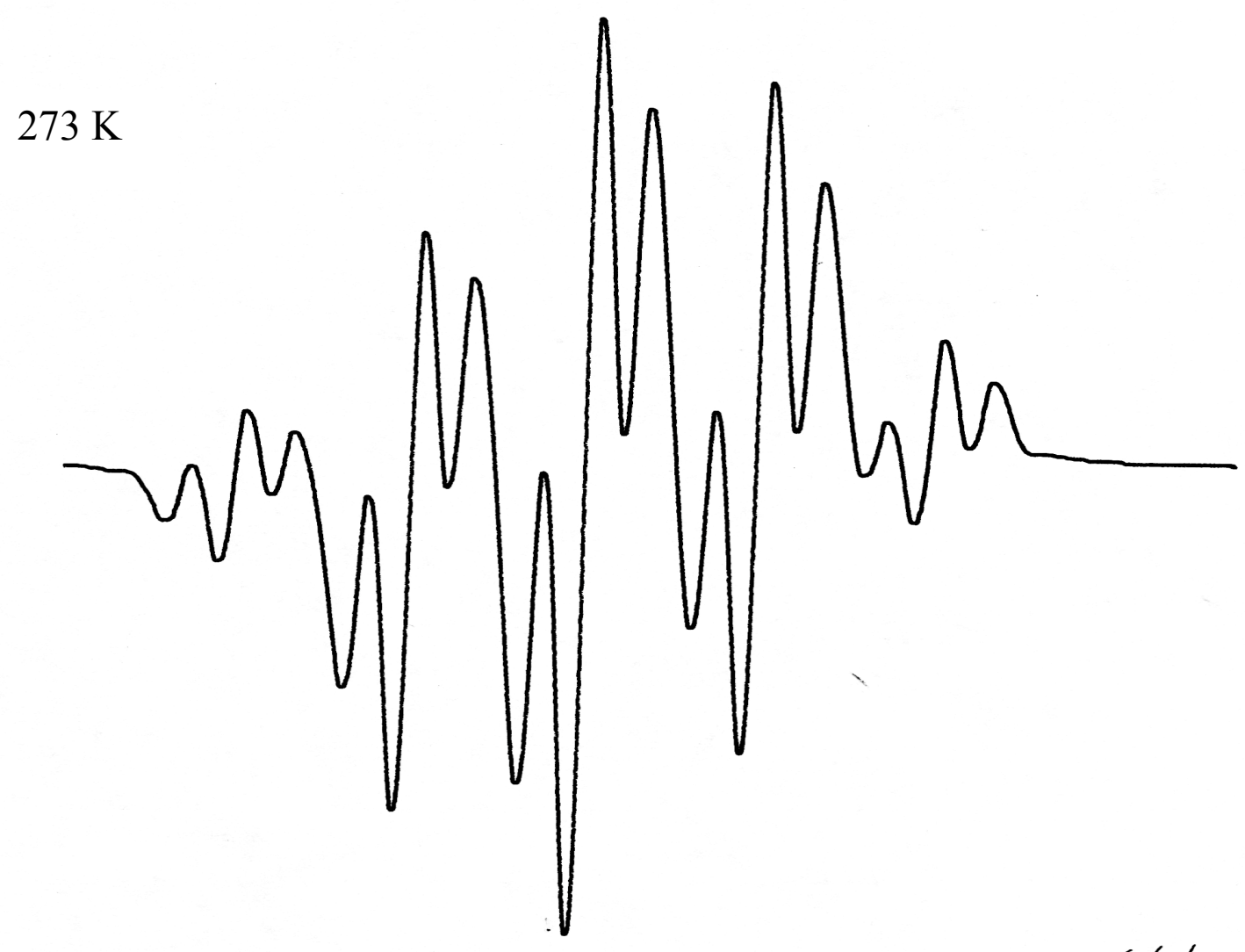

$213 \mathrm{~K}$

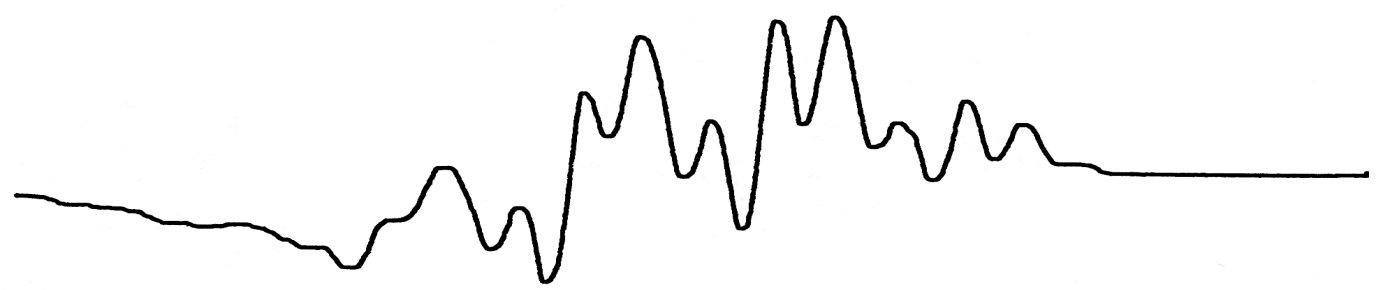

Figure S1. Typical change of the ESR spectrum of phenalenyl radical $4^{*}$ (5 $\mathrm{mM}$ in chloroform) showing dramatic intensity decrease upon lowering the temperature 

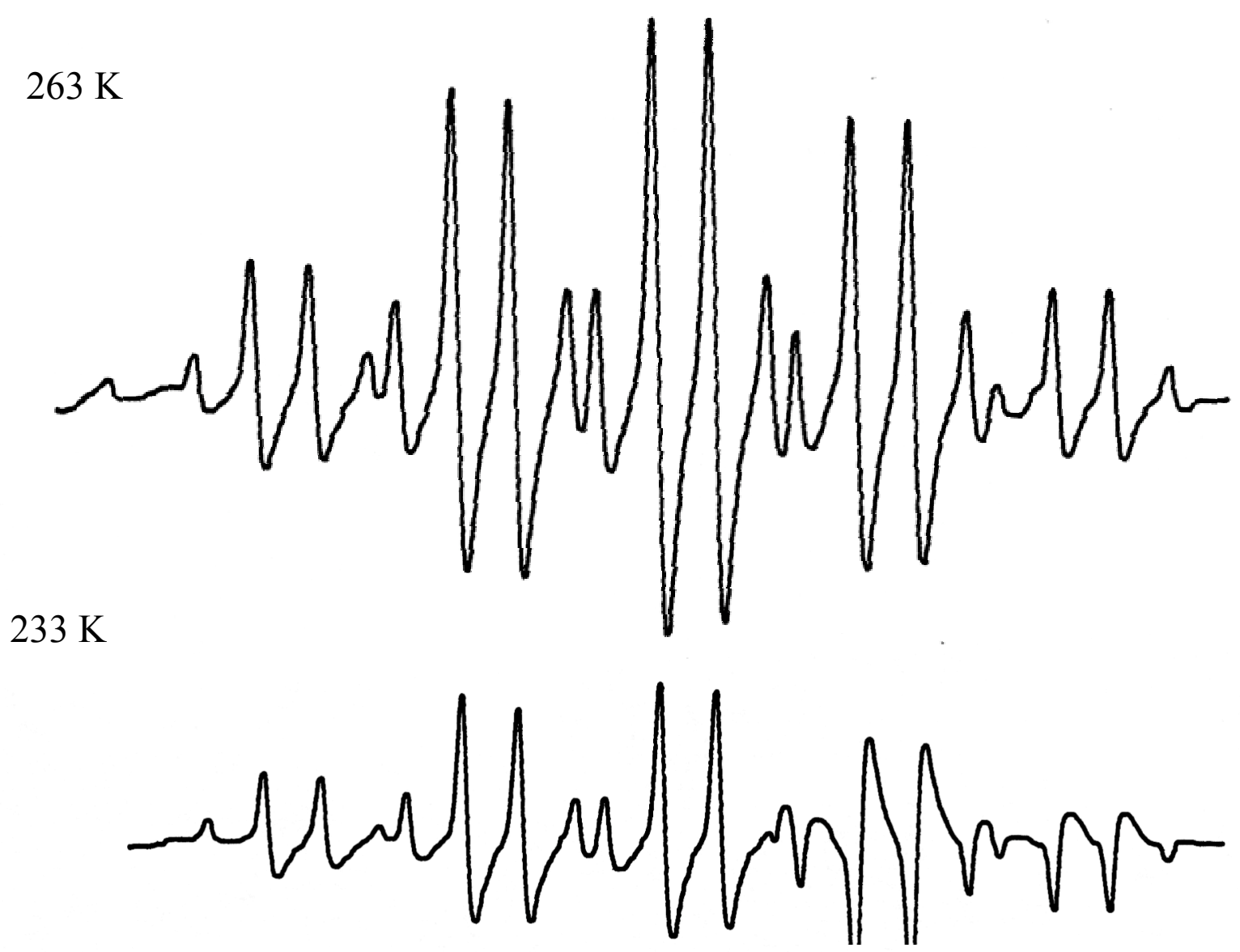

$203 \mathrm{~K}$

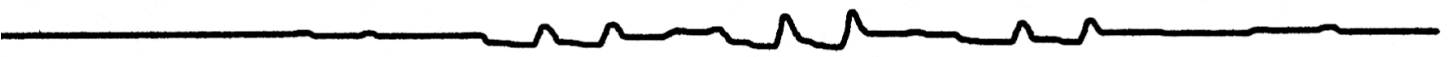

Figure S2. Temperature-dependent ESR spectra of phenalenyl radical $\mathbf{1}^{\bullet}(1 \mathrm{mM}$ in dichloromethane) showing the striking diminution of signal intensity. 